\title{
Becoming in STEM: Developing a Culture of Criticality in the Space Between Person and Institution
}

\author{
Angela Calabrese Barton ${ }^{1 * \dagger}$, Edna Tann $^{2 \dagger}$ and Autumn McDaniel ${ }^{3+}$ \\ 'Educational Studies Department, University of Michigan, Ann Arbor, MI, United States, ${ }^{2}$ Department of Teacher Education \\ and Higher Education, University of North Carolina at Greensboro, Greensboro, NC, United States, ${ }^{3}$ Boys \& Girls Clubs \\ of Lansing, Lansing, MI, United States
}

\section{OPEN ACCESS}

Edited by:

Marta Soler-Gallart,

University of Barcelona, Spain

Reviewed by:

Javier Diez-Palomar,

University of Barcelona, Spain

Lina M Trigos-Carrillo,

Universidad de La Sabana, Colombia

*Correspondence:

Angela Calabrese Barton

angieCB@umich.edu

${ }^{t}$ These authors have contributed

equally to this work

Specialty section:

This article was submitted to

Educational Psychology,

a section of the journal

Frontiers in Education

Received: 22 October 2019

Accepted: 25 March 2020

Published: 21 April 2020

Citation:

Calabrese Barton A, Tan E and

McDaniel A (2020) Becoming

in STEM: Developing a Culture of Criticality in the Space Between

Person and Institution.

Front. Educ. 5:37.

doi: 10.3389/feduc.2020.00037
In this article we present a study of a youth, Fall, tracing her STEM engagement from grade 5 through high school, across STEM spaces both formal and informal, utilizing critical, longitudinal ethnography. Drawing from social practice and critical justice theories, we present how Fall's STEM history-in-person collided with the history-ininstitutional-struggles, as a White girl growing up in multi-generational poverty who eagerly engaged in what she calls "science that matters." We present how Fall enacted commitments-in-practice, in conjunction with three related, local contentious practices, leading to the emergence of a culture of criticality. We theorize how the space between person and institution became and functioned as an incubating space, supporting Fall's authoring of a new chapter in her STEM history-in-person.

Keywords: critical longitudinal ethnography, criticality, history-in-person, STEM, social practice theories, justice

\section{INTRODUCTION}

No one ever really thought I could do much, and so I don't think people care whether I become a hairdresser or not. But, I'm good at it. I do my friends' hair all of the time. I can do white hair and black hair. I have been in (my STEM community club) longer than anyone! I have been in it since 5th grade. That is like six years. I could do things there. I made a PSA (public service announcement) about water efficiency with my friends. I showed it at school, and people saw what I knew. I taught them something. It got me thinking more about how I want to be a green hairdresser. Fall ${ }^{1}$, High School Sophomore

At the time we conducted this study, Fall was a White girl growing up in multi-generational poverty in an economically challenged Midwestern city. She has attended public schools which serve significant populations living in poverty, replete with overcrowded classrooms, high teacher turnover, out-of-field teaching, and limited STEM resources. Fall also struggled academically in school, repeating levels in elementary school twice, making her 2 years older than her peers by the time she graduated high school. Her sixth grade teacher described her as a "struggling reader and writer." Her seventh grade teacher labeled her "a kind but quiet girl in the background." When she was 14 , her mother told us that "if she would just get D's, I would be happy."

Despite these circumstances, Fall authored a STEM-empowered life against the dominant sociohistorical narrative in American society. As the opening quote indicates, Fall noticed that the adults in her life "don't care" what or how she becomes in life. Yet, Fall sees her experiences as valuable and worthy in both STEM and the world. We followed Fall for 7 years, from 5th grade through high school, in school, afterschool, and amongst family and friends. During this time, Fall shifted from wanting to be a hair designer (5th grade) to owning a "green" (environmentally

\footnotetext{
${ }^{1}$ All proper names in this manuscript are pseudonyms. Youth pseudonyms were self-selected.
} 
friendly) hair salon (8th grade), to considering geological engineering as a possible career (10th grade). During high school, she spent 2 to 3 days after school, nearly every week, in a makerspace housed in her local community center, building things to solve people's problems and mentoring newcomers to the space. During this time, Fall built a Little Free STEM Library, led workshops on energy efficiency tools, authored educational movies for her community on sustainability, and served as the chief blogger for her afterschool STEM club.

Fall's journey has been complex and riddled with tension. She not only bumped up against the structural barriers imposed by schooling and society as a girl growing up in poverty, but also, enacted a way of becoming in STEM that differed from legitimized forms of participation. She cultivated her expertise among friends, and in her afterschool club, as she also built a strong alliance amongst her Black friends. She also sought to use her knowledge and experience to engage with her local communities on addressing shared challenges and needs. This stands in contrast to cultivating an individualistic school knowledge for the purposes of good grades and college trajectories. For Fall, becoming in STEM is less an individual "I" - process of becoming in relation to the other, but rather a humanizing, critical and collective endeavor - "I/We" (Urrieta, 2019) - to transform the practice of becoming for herself and her community. Becoming in STEM was also Fall's primary experience of authoring a personally meaningful "I/We" collective in her life thus far.

We are interested in Fall's engagement with others and STEM over time and space as central to learning, and how this has shaped her becoming. The overarching question that guides this manuscript is: What are the interactional forces operating across space and time that influence Fall's becoming in STEM, as a White girl, growing up in multi-generational poverty in a Midwestern city? How do the locally contentious practices Fall authors support transformative learning?

Using Holland and Lave (2009) two forms of history "history-in-person" and "history-in-institutionalized struggles" we examined several pivotal events, and the micro-dynamics at play, identified by Fall with respect to becoming in STEM for herself and her community. We sought to make sense of the ways in which Fall's STEM experiences were carried out in local practice but also enacted against the broader background of sociocultural/historical narratives. In this process we traced Fall's core commitment-in-practice in STEM and Community. We also examined how this core commitment-in-practice led to conflict and new forms of "contentious local practice" as her commitment-in-practice, in its varying forms, pushed back against particular local, historical and sociocultural contexts.

\section{BECOMING IN PRACTICE}

\section{A Critical Justice Stance}

Recent work on studies of girls' identities and learning in STEM in low-income communities points to the importance of the intersecting role of structural and curricular inequalities in spaces intended to increase access and opportunities such as STEM schools (e.g., Weis et al., 2015). However, few studies in STEM education examine deeply how these intersectional geometries of power shape opportunities to learn and become. The 2018 science and engineering indicators reported by the National Science Board (2018) showed that women made up $28 \%$ of employees in science and engineering occupations, with White women employees at $64.9 \%$ of that total. However, the study does not offer an intersectional look at White women, with the socio-economic backgrounds of the women unreported. We thus sought to advance what we know by delving into the experiences of a White girl growing up in multi-generational poverty.

Our study is grounded in a critical justice view of equity (Balibar et al., 2012) and a social practice view of learning (Holland et al., 1998; Holland and Lave, 2009). Equity, in STEM education has centered on the importance of access and opportunity to high quality instruction and to disciplinespecific activities. Attention has also been paid to how such learning opportunities mediate outcomes, defined through the development of disciplinary knowledge and practice, identities, interest, and future pursuits (Horn, 2018).

However, how children experience these opportunities, are mediated by forms of structural inequalities perpetuated through systemic sexism, racism, and classism. Such structural inequities are experienced daily, in local practice, through traditional patterns of participation in science (or any discipline) to expand upon who and what areas of expertise are recognized and valued, disrupting participation boundaries and knowledge hierarchies (Jurow and Shea, 2015). A critical justice stance on equity challenges the conceptual and political underpinnings of equity in science education by putting attention on the need to re-shift relations of power and position within science education and its intersections with historicized injustice (Bang et al., 2016). This stance foregrounds attention to making visible and upending injustices located in current practice but grounded in historical, social, and geographic histories (Balibar et al., 2012).

\section{Social Practice Theory: Becoming in Practice}

Social practice theory frames becoming through one's on-going social existence in the world. As people move through time and space they are exposed to, positioned by, and react to a range of people as well as institutional and cultural structures and forces (Holland et al., 1998). Quite different from the psychological framing of identity as an internal attribute, social practice theory frames becoming through how people come to be in social context; where people figure themselves and are figured by others as they "adapt to author themselves in the moment" (Holland and Lave, 2009, p. 4).

We chose this theory due to our interest in "understanding and explaining real, everyday, situated activity in its concrete, material detail" (Roth, 2006, p. 608), especially in light of how these processes transpire through the historical, cultural practices of everyday life. Who youth are and seek to become are influenced both by how they are positioned by others as well as how they position themselves within the valued cultural practices of their communities (Allen and Eisenhart, 2017). By 
emphasizing the historical production of persons-in-practice, social practice theory calls attention to the "differences among participants" and "the ongoing struggles that develop across activities around those differences" (Holland and Lave, 2009, p. 5). A person's becoming, made visible through interactions and taking up new practices, is not separate from their personal histories nor broader sociohistorical narratives.

Urrieta and Noblit (2018) point out that processes of becoming are always about power because they are about who counts as somebody who belongs. Power-mediated relationships and interactions shape youth's becoming in powerful ways. Fall was not only labeled a "struggling reader" but also placed in special education courses where her access to STEM was truncated. Her progress was measured by her disabilities (e.g., struggling reader). Opportunities to be recognized for her STEM curiosity and activism were structurally limited for her, at least in school settings.

Fall's opening quote illustrates how she encountered but also became a part of the powerful narratives, traditions, and histories that demarcate what it means to be a particular kind of person in science. Fall, like all learners, encountered broader disciplinary, school-based and cultural narratives around what it means to be scientific, a good student, or a girl growing up in poverty. These broader narratives play out through the relationships and activities that students engage in at any given moment.

Acts of becoming are thus always tension-filled, for how one is recognized within communities of practice is an artifact of the power dynamics that operate there (Nasir, 2011). The processes of becoming, which always take place in-the-moment, in local activity, also happens within and against local norms and expectations and as a part of longer standing sociocultural and historical narratives. Social practice theory provides a lens to examine the ongoing struggle between personal and historical narratives influencing participation with science by integrating "the study of persons, local practice and long term historically institutionalized struggles" (Holland and Lave, 2009, p. 1). The relations between history-in-person and historyin-institutionalized struggles, erupt primarily because local practice(s) comes about in the encounters between "people as they address and respond to each other while enacting cultural activities under conditions of political-economic and culturalhistorical conjecture" (p. 3). Local contentious practice can be thought of as the critical stuff of becoming.

\section{Local Contentious Practice: Critical Justice and Becoming}

Juxtaposing social practice theory with critical justice allows us to make sense of how two forms of history - "history-in-person" and "history-in-institutionalized struggle" (Holland and Lave, 2009) yield pivotal interactional practices, and how the micro-dynamics at play, create (and foreclose) opportunities for transformational agency (Bang et al., 2016). Personal experiences carried out in local practice are enacted against the broader background of cultural and historical narratives. We want to delve into the kinds of contestations that make up local contentious practice in order to unpack how Fall's commitment-in-practice takes shape over time, maintaining and transforming both person-in-history and enduring struggle. This approach "demands relentless attention to how material economic practices, power relations, and the production of meaning and difference constantly play upon one another" (Hart, 2002).

We see this in Fall's story as she encounters societal narratives about what it means to learn and do science as a young, female, from a low-income background juxtaposed with her personal narratives of doing science in and for her local community. This often plays out in struggles between the ways in which schools value Western ways of knowing and doing science and the cultural meaning making practices youth bring with them from personal experiences. The intersection of these histories impact conceptions of what it means to be scientific, who can do science and where science is meaningful.

The struggle between the two forms of history also influences individuals' actions in local practices. The institutional and personal narratives experienced or brought into the classroom hold specific meanings for the actors in this space. Holland and Lave (2001) argue "cultural genres" that "rule in social life" are:

associated with particular persons or groups of people identified in social space and historical time. Practices and discourses become markers of their owners and evoke their social image. They carry with them the aura or, to use more sensuous metaphors, the images and the odors of particular others, particular professions, particular social groups, particular individuals with which they are associated (p. 16).

In our work presented herein, we sought to make sense of the ways in which Fall's developing STEM knowledge and practice were carried out in local practice but also enacted against the broader background of cultural/historical narratives. We traced how Fall sought to take action with her developing science knowledge, and how she bridged or positioned it alongside or against community knowledge and practice. We also examined how these differing epistemological groundings, at times, gave way to conflict ("contentious local practice") as Fall pushed back against particular local, historical/sociocultural context.

\section{METHOD}

Critical, longitudinal, participatory ethnography was our selected methodology because of its explicit focus on participatory critique, transformation, and social justice. This hybrid form of ethnography is grounded in the idea that researchers and participants can use the tools of ethnography (embedding ourselves in context), to conduct empirical research in an unjust world in ways that examine and transform inequalities from multiple perspectives, leveraging both emic and etic perspectives (Trueba, 1999). The work is critical in the sense that we pay attention to and seek to challenge the powered interaction between actors and the social structures through which they act, given that these relationships are never neutral. Lastly, this work is participatory in the sense that the youth in our study were active contributors to the questions we asked, to the data we generated in its forms and in the roles such data played - as well in the construction of the narratives we tell about the data. 
We collaboratively decided with Fall to tell her story as a single case study in order to delve into how the local manifestations of intersectional geometries of power shape Fall's opportunities to learn and become. As noted in the introduction, Fall, a White girl, growing up in intergenerational poverty. When we first met her, she lived with her parents, and two siblings (an older sister and younger brother). Over the course the years we knew her, her father passed away unexpectedly, her brother moved to a state far away to re-start his life as openly gay, something he felt, and Fall concurred, was not permitted in his family, and Fall herself moved in with her best friend, who is Black when she became estranged from her mother. We mention that her best friend is Black, in part to note that part of Fall's experiences growing in a predominantly Black community shaped her most powerful social alliances. In a notably segregated city, this was not the norm.

The economic stressors on Fall throughout this time were profound, and took form in food insecurity and sometimes bullying for lacking things she could not afford (e.g., up-to-date stylish clothing and other material items). In tenth grade, she began working at a fast food restaurant to earn an income, and relied on her school, the club, and her fast food job to provide her with access to free food.

Despite these challenges, Fall nearly always held a cheerful and caring demeanor. She consistently leveraged the resources she had access to help those around her. For example, one afternoon, she brought enough "mini-frosties" to her afterschool STEM club for everyone, including the adult teachers, to enjoy. On another occasion, when one youth was distraught that the umbrella they were using was torn, on her own initiative she located the sewing kit and patched it back together.

Her experiences in schooling reflect the historicized experiences faced by many youth growing up in extreme poverty. She attended under-resourced schools where literacy and mathematics dominated instructional time. She was held back twice for reading below grade level. Her remedial reading support pulled her out of the classes she enjoyed most, such as science, which was only offered once or twice a week.

However, at the same time, Fall's afterschool club - a vibrant community center serving over 350 low-income youth daily was a key resource. She spent most days after school at the club, even as she got older, if it did not conflict with her work schedule. Her club provided snacks, homework help, and a range of activities and programs. Fall participated in the STEM programs from 5th grade through high school. It was in these STEM programs that we got to know Fall, as we served as educators, mentors and researchers in many of them. For example, Fall was a core member of her Green Club, and as noted earlier, the chief blogger for the club. Green Club, open to any middle school youth interested, was offered twice a week, year-round, with full time summer camps. The core philosophy of Green Club was to support youth in naming, investigating and taking action on science-related issues that matter to youth and their communities. She also participated in her "Innovators" Makerspace at her community center during her high school years. This program also met 2 days a week, with a third day for "open make." This program leveraged upon pedagogies of community ethnography to support youth in putting their making efforts in dialogue with community members. Like Green Club, the authors of this article served as educators, mentors, and researchers.

By telling Fall's narrative we seek to build deeper understandings of how new local contentious practice can emerge in ways that re-enact, reform and refine opportunities to learn and become. In particular, this single case study is meant to leverage upon a nuanced examination of Fall's experience, across setting and time, to build new theoretical knowledge of how intersecting inequities shape opportunities to learn and become (e.g., Weis et al., 2015). We take a transgressive approach to validity in this work, acknowledging that the uses of the theoretical insights generated herein are oriented toward challenge traditional authorizing criteria for what it means to develop understandings of becoming in STEM.

Written and informed consent was obtained initially from Fall's parent for all data generated prior to her 18th birthday, and then from Fall, herself, as a legal adult, for all data generated thereafter. Consent includes the publication of indirectly identifiable data as well as verbatim quotes.

To collaboratively tell Fall's story, we draw from three data sets.

First, Fall co-constructed a portfolio of her learning and participation in STEM across the spaces of home, school and community, pulling in events and experiences from the 5th through the 12th grade. During a 10-week period though spring/summer 2017, Fall worked with us to create a collection of artifacts together representing her pathway through life with and in STEM learning and practice. This collection included a multimodal slideshow presentation featuring photos, videos, screenshots of blog posts she had authored, and text she produced to introduce a chronological storytelling of her life's work so far to various stakeholders of interest (e.g., her current teachers, professors at her local state university, science education researchers at national conferences where she presented, and future employers). Fall was able to access these artifacts through a folder we generated of materials we had collected over the years that we knew her. However, she also created new artifacts for the purpose of this portfolio, such as video reflections and images of science in her home and community. It also included a written complementary artifact, a co-constructed narrative of her efforts to be and become in STEM prominently featuring a transcribed "Q and A" style narrative interview between Fall and an adult mentor.

Second, the researchers kept ethnographic data files on Fall's experiences over the same time period. These data also included Fall's participation in weekly conversation groups during the Spring semesters 2010-2012, that were part of her afterschool STEM club. Videos of afterschool and community participation in STEM captured as part of regular records of practice documentation (twice a week, Fall and Spring semester, 2010-2017, and weeklong summer camp experiences), twice yearly interviews each of the years that Fall participated in our afterschool STEM programs (2010-2017), and photos of artifacts she produced during these times, such as her on-going work on the little free library. We also collated all of her blog posts produced between 2015-2018. These data are comprehensive 
and reflect Fall's experiences in STEM as she progressed from elementary to middle and through high school. Fall also culled through these to help with her portfolio construction.

Third, we conducted extensive portfolio dialogues with Fall. These conversations were held to make sense of her portfolio and why she constructed it as she did (e.g., what the different events, people, resources, power dynamics named mean to her), as well as how she describes the importance and impact of these events. Conversations took place once a week, after school, during the fall 2017 and spring 2018 semester. These conversations include co-construction of Google slides summarizing key ideas and insights, and involved an-going production of a timeline of events and experiences. For example, one key theme that emerged in these conversations was what we eventually refer to as "commitments-in-practice." We worked to describe the commitments and practices she felt made up the pivotal moments in her portfolio. In another example, we also sought to identify and name the tensions that emerged, in particular, as she enacted her commitments-in-practice in STEM.

We examined data for continuities and contradictions using critical inquiry/grounded theory approaches consistent with relational ethnography to "puncture deeply held methodological preconceptions" as we seek greater political clarity in the analysis process itself (Charmaz, 2017, p. 1).

The first phase of analysis took place during the portfolio conversations noted above. During these dialogues we collaboratively open coded the portfolio. This processes produced an initial set of categories of ideas that we eventually named commitments-in-practice. We also generated a list of critical moments and tensions. In addition, we thoroughly perused all generated data (e.g., transcribed interviews, observation fieldnotes) to further surface additional insights on the ideas emergent from the dialogues, but also to surface new codes. We sought to deepen our understanding of the critical episodes of STEM engagement that Fall leveraged in some way for STEM engagement (e.g., group activities in science class or informal science spaces that featured particularly salient performances, in talk and actions) especially vis-a-vis the commitments named by Fall. This included new codes on how Fall positioned herself during critical episodes; how she responded to how others positioned her within these episodes; and the importance, meaning and roles of the artifacts Fall highlighted as most representative of her commitments-inpractice. Weekly conversations were held between the authors as a way to work toward a more expansive consensus. Differences in views were debated until new meaning was generated. A detailed list of emergent open codes were kept with analytic memos which we then brought to bear on the second pass at axial coding.

During this second phase of coding, we paired the critical moments with the commitments-in-practice to deepen our insight into how and why Fall enacted her named commitmentsin-practice. We made note of when these commitments-inpractice created new opportunities and spaces for becoming in STEM (especially when these were previously denied), and what this looked like for fall. We also noted when they did not. With the help of our theoretical framework, we then worked to make sense of what it meant for Fall to enact her commitment-in-practice through history-in-person and history-in-institutionalized struggle as we further sought to establish relationships between these commitments-in-practice and emergent tensions. This axial phase of coding was used to uncover relationships and connections between the Fall's STEM engagement and the tensions/conflicts that emerged. We took these data points as markers of new local contentious practices and sought to connect these back to Fall's commitmentin-practice. Embedding ourselves longitudinally in contexts with Fall helped us to make sense of the relationships and relevant background happenings that shed crucial light on these "snapshots" across time that we share below.

\section{FINDINGS}

Below we trace Fall's core commitment-in-practice - a commitment to community and in community - and how this commitment took shape as she moved across the spaces of home, school, and afterschool during the middle and high school years. We use the phrase commitment-in-practice to indicate that this commitment took shape through social interaction, where people and contexts exerted significant influence, both supportive and otherwise, on how Fall adopted or authored her commitment. In elaborating on how Fall enacted her commitment-in-practice through history-in-person we describe key events, which Fall indicated reflected her embodied commitments. In describing these events, we draw attention to how Fall's commitment-in-practice emerged, in part, from her having a space or platform for her to try out and refine these commitments with and against the enduring struggles she experienced in STEM and schooling.

We also examined how Fall's commitment-in-practice to community and in community led to conflict ("contentious local practice") as these commitments challenged particular local, historical/sociocultural norms. Three particular contentious local practices that Fall enacted are also described, related to: (1) authority to name what counts as STEM; (2) awareness/discourses of STEM; (3) access/participation in STEM. In this second part of these findings we trace these events longitudinally, as they intersected and built on/with each other, and in different contexts. By telling Fall's narrative this way, we draw attention to how Fall's enactments of her commitment-in-practice clashed, at times, with history-ininstitutionalized struggle, leading Fall to engage in forms of local contentious practice that became re-enactments, revisions and refinements of her commitments over time (either individually or in combination, Figure 1).

\section{Commitment-in-Practice: A Commitment to Community and in Community A Commitment to Community and in Community}

Fall engaged a commitment to community and in community as integral to becoming in STEM as she navigated home, school, and after school. By a commitment to community we suggest that Fall worked to understand, connect with and critically care for the people in her community, especially as 


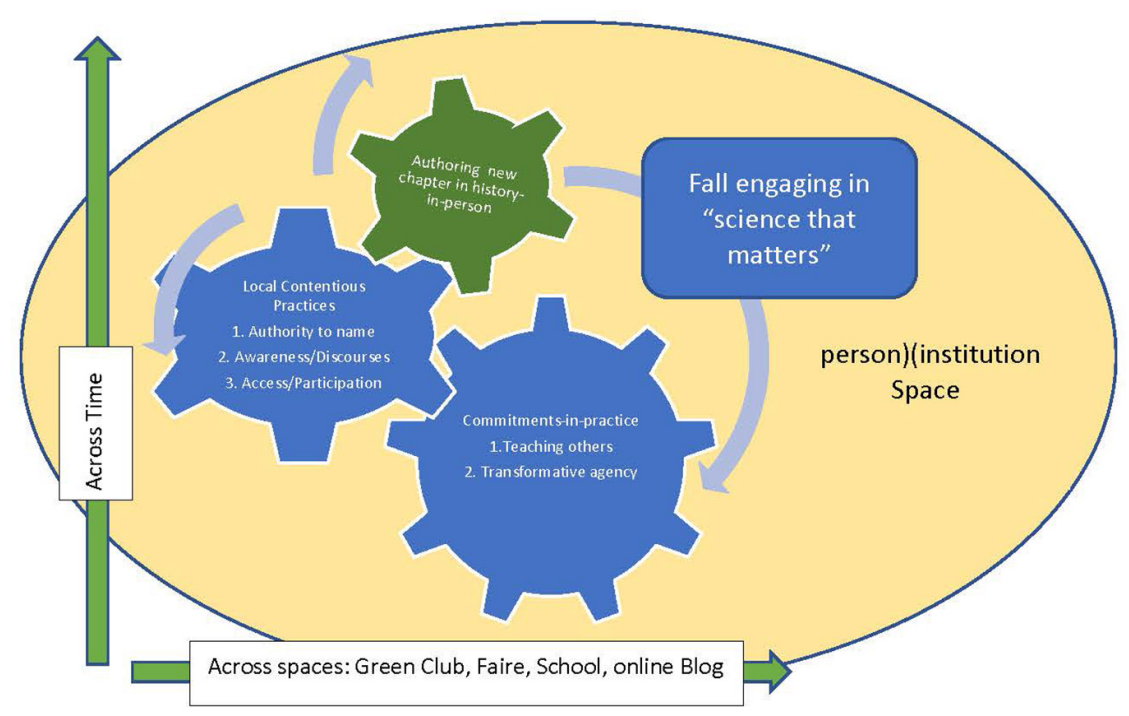

FIGURE 1 | Relationality between Fall's commitments-in-practice, local contentious practices in the process of authoring a new chapter in her STEM history-in-person.

she built multi-generational and cross-cultural alliances, and her role in actively disrupting the historical, hegemonic structures and practices that oppress members of her community. Fall's community is largely comprised of low-income families, most of whom are Black, and nearly all of whom, like Fall, have experienced multi-generational poverty. The unemployment rates in her part of the city are nearly double that of the state average, despite the slow economic growth recently experienced across her state. During the height of the economic recession (about the time Fall entered middle school), her family and her friends' families were all out of work.

Fall's commitment to community and in community centered a collective struggle to imagine and build a more just world. This commitment enacted in practice, in part, by Fall's efforts to leverage upon her interest and knowledge in STEM to identify and take action on the problems her community faced, such as high energy bills, limited access to resources, and poor air quality. As a White girl with a predominantly Black network of friends and supports, her views were tempered by her understanding that scientific inquiry is, itself a political project, shaped by and giving shape to the power-mediated boundaries of race, class, and gender, that influence one's experiences and understandings in/of the world. She ardently supported the rights of her peers to have opportunities for STEM learning, contributing to efforts to lobby her school to deploy energy efficient technologies in their school to save money for afterschool STEM programming. She also blogged about her peers' accomplishments, celebrating their STEM achievements with special attention to how those achievements made a different in their community. This is evident in her blog post about her peers' efforts to prototype a functional light-up, heated boot for people in need in her community.

Fall also enacted her commitment to community and in community by collaborating with her peers and community educators to create STEM learning opportunities for her community. These workshops, led by youth, and offered in interactive and inclusive ways for her Black community, challenged who has the right to provide access to STEM, how and why. Further, these learning opportunities centered youths' cultural practices and community networks of support, making these "STEM by us and for us" as she described her participation in a large Green Carnival she and her peers put on to share free resources and information about energy efficient tools and resources in support of her community both saving money and the environment. She noted, "That was literally like the first real time I knew I could make a change. We got everyone at the club. And there was hundreds of people. We had to do it. We got everyone food and materials to take home and they had fun as they tried our experiments and danced and stuff." She referenced how important it was to engage her community in joyful ways around serious issues that made a difference in everyday life.

Along with peers and allies, Fall leveraged upon the knowledge and practice of STEM, alongside the wisdom of her community, to cultivate a kind of transformative agency elemental to community-centered inquiries. We take up both points below.

\section{Creating Spaces of Learning and Engagement in STEM for Those in her Community}

Fall explained that one of the most important enactments of her commitment was, "teaching others ... kids, teachers, my family and people in the community." For Fall, teaching others was about "bringing people together" in considering "how (science) matters here." Instead of science presented as decontextualized from where people live and who they care about, science with a commitment to community involved using the knowledge and practices of science to make a difference through taking action upon community-related concerns, as the Green Carnival example earlier illustrates. This was more than grounding an investigation in an area of interest to youth. According to Fall, it 
meant youths' experiences in their community were central to the investigation because they engaged community members toward real and consequential action taking on issues mired in injustice.

Fall's commitment-in-practice is attuned to the power of leveraging developing knowledge of "community STEM expertise" to teach others - across settings - (a) science content in accessible ways, (b) what one can do with science other than science class, which include investigations to save money and the environment, (c) how to use science to make a difference at school, and at home, (d) how teachers can do more to attend to their students' diverse learning needs and interests, through her active efforts to model more equitable and youth-centered teaching practices ("Because, you know, nobody wants to just sit down and read paragraphs from a book and write down the questions and answer them"). This commitment-in-practice matters to Fall because "in school we don't really do real science." "we just learn things," "we don't do anything with it."

Fall cited her experiences in her afterschool Green Club, Girl Scouts, and at home, as places where she has "done things" with science that carry meaning for her or her friends and family. Teaching, for Fall, meant offering practice-based access to STEM in ways that integrate her desires for and agency to make a difference. Importantly, she distinguishes her definition of teaching from a more lecture-based, authoritative repertoire of practices she has observed and experienced in formal education.

\section{A "Most Powerful" Enactment}

In her STEM pathways portfolio, Fall indicated that the most powerful example of enacting her commitment to community and in community was when she taught her 6th grade science class about water and energy efficiency toward environmental and economic sustainability. This was a lesson she created with two friends that used a video and an investigation she created and perfected in her afterschool club. In her portfolio, she included $5 \mathrm{~min}$ and $42 \mathrm{~s}$ video clip of this moment in her classroom. As she stated about this portfolio entry: "teaching my classmate about the projects that I did because some of them liked it was helpful to my classmates and teacher, and so they would know there are other things besides science class that you can do with science."

In this episode, Fall along with two friends, took what they had learned about energy efficient technologies and behaviors from their STEM after-school community club, to younger students and peers at her school. Fall wished to do this because she wanted her peers, who attended a school stressed for resources, with limited time for science, to be able to "know what I know." Fall's afterschool teachers helped she and her peers to organize and practice their lesson, and worked with Fall's classroom teacher to create space for them to do this. Fall and her friends prepared a PowerPoint and led the class through a hands-on, interactive experiment looking at the difference between CFL and incandescent light bulbs. Their goal was to help students to experience how and why energy efficient light bulbs were both good for the environment and for their energy bills.

The lesson began by Fall surveying the students in her class about what types of light bulbs they use at home before asking them to predict the efficiency of three different kinds of light bulbs presented (incandescent, CFL, and LED). Fall began the lesson by saying, "Let's compare light bulbs to see if CFL light bulbs and LED light bulbs can save energy. Like, this is the CFL and that is the incandescent." After her partner informed students that they would be measuring energy using a watt meter, Fall asked for volunteers to predict how many watts each bulb used. Fall called on students as her friend noted students' predictions by repeating each guess. But then her friend, who was a "star student" and was supposed to lead the next part of the lesson, suddenly froze, unable to facilitate the next part of the lesson. After a brief pause, Fall jumped in and took over the rest of the lesson. Fall focused the class on collecting data by saying, "OK, let's measure how much energy each light bulb uses." She called on students to read the watt meter for the different bulbs. Fall then asked, "What did you notice about the amount of energy used between a CFL, LED, and incandescent light bulb?" The video clip ended with students discussing what they noticed and what that means for the amount of energy they use at home. She then guided the students to brainstorm the ways they could use these ideas in their own homes to save money and the environment, praising each students' ideas as "great" and "will make a difference."

In this particular classroom, the teacher had previously described Fall as a student who is just "lost in the background." In his words:

\begin{abstract}
There are no expectations on Fall at all. Mom and Dad don't even like to talk about Fall at school. They just say that she has problems. She is in the special ed room and she has problems. If she could just get D's we would be very happy with that. So, she doesn't have a whole lot of expectation on her as far as school goes which is sad. When you talk about Peter (her brother), their whole world lights up. So that is just who she is at home, she is that kid. So that is a little background on our friend Fall here, but a really nice kid.
\end{abstract}

In this vignette, we see how Fall was becoming through commitment to her peers and their families by transforming what science learning and engagement could be in ways that translated into home practices that mattered specifically in her community - a community where many families were out of work - as she unexpectedly stepped up to the plate and taught the lesson because a peer unexpectedly could not. The teaching act made Fall a teacher, and started to draw from her a deeper commitment to teach that became consistently evident in her future engagements with STEM.

Fall noted that teaching helped her classmates become "more active in science class" and "learn more science" in ways that were "fun" and "actually matter." Fall said that by "teaching my class I am also helping my community because, well like, when we were doing the CFL light bulbs that was teaching my community that if you are using incandescent you are using more energy and spending more money than if you were using CFLs."

\section{Orienting Toward Transformative Agency}

While related to teaching others, Fall separated out the importance of "doing something" - or what we call transformative agency - as critical to her commitment to community and in community. For Fall, helping others, apart from teaching them about something, also involved using what 
she has learned and done with science to "take action." She noted that "lots of kids don't have things" and "have alot of unfair things happen." Here she was referencing both the economic challenges faced by her community, as well as the entrenched racism she witnessed her peers experienced daily. She reflected upon her own situation, where she felt she did not have the experiences at home or at school she needed to help her learn to read or write better at an earlier age, even though she had an Individual Education Plan. She reflected on the time she worked on a water efficiency video with two friends - "they are smarter than me" - but who made a welcoming space for her in their group project. She described how they helped her with the "hard parts" of the video such as describing water efficiency and calculating how efficient devices translate into money and carbon savings. She also said she helped them because she helped to choreograph the "water dance" and ideas for how the movie could go. She also said she was a good collaborator.

For Fall, transformative agency involves (a) figuring out what other people's concerns are and how to address their concerns, and (b) being patient and open to what people need or care about. For Fall, this critical and caring form of action taking involved working on large and/or long-term projects, such as the Little Free STEM Library (detailed below). However, it also involved smaller actions, such being a mentor in her maker club. As she noted, "Instead of me doing my own project I wanted to help other people with their projects."

\section{Why Transformative Agency Matters}

Fall says that the best example of transformative agency is her work on the Little Free STEM Library. In 10th grade, Fall conceptualized, designed and built a Little Free STEM Library at her local community club. She felt that access to STEM books would help others learn to read and engage with science, aspects limited in her own schooling. She included mini-maker kits so that others could "make the things that (she) had a chance to make (at the club)." She added an eye-catching LED lighting system powered by a handcrank generator, which would be "good for the environment," and "get (kids) curious." She describes the project as one that she "worked on the hardest ever."

Fall was concerned that children in her community have time to read while also having the chance to "make things" - concerns she felt were not adequately addressed at school, concerns also central in her own life.

Over several months, with help from her after school teachers, she researched the need for a library, and possible styles and wood types. She drew up blue prints by hand, then in a threedimensional sketching program. She cut and assembled the wood. With feedback from peers, she added a door and a lighting system powered initially by a handcrank generator. She continued to work on the project the following year making it more accessible, changing the lighting system, and expanding the materials shared inside.

She notes of the Little Free STEM Library: "The Little Free Library shows that I want younger kids to learn to read and learn different science books and stuff." Furthermore, Fall believed that the Library's impact went beyond the artifact itself in how it inspired others to take action, too. She explained:
Some teachers make you feel that you can't be accomplished in life. With the Little Free STEM Library I felt accomplished. The Library helps kids practice reading and learn more about science. If kids live in a library desert like us it really matters more. If we were over in the south side where I live, people would be like "that is cool!" If we go to the east side and they could learn too and make a difference too! Then they would reach out to other communities, and it would just keep growing and growing.

When reflecting on the importance of transformative agency in her commitment to community, Fall selected the following blogpost (January 2016) to illustrate these points. She wrote:

Today I worked on the little free library that we are putting in the Boys \& Girls Club. I got A LOT done so far. It looks amazing! Just like our blueprints! I wouldn't (have) gotten as far as I did if Danny and $K$ wasn't helping me put it all together. We still have A LOT of work to do, but once we get it done. It's gonna be the first thing I have done in a while! I can't wait to see what it turns out to look like. I can't wait for the kids to get books to read. Thanks so much for helping me work on it Danny, and thanks for getting all of the materials for me Angie, Y'all are the best!

Fall said this post showed how hard she worked with the help of mentors and peers, and how important the library was for other kids to learn to read. She said that she knows how hard it is to learn how to read, given that she has been in special education and labeled a "struggling reader" but she always felt that she never had a chance to just practice with books at home or school.

Fall also liked that the blog post showed her working with her afterschool STEM club mentor because that "was a big part of it." She used the photo from this blogpost as the screen saver on her laptop she earned for being a mentor in her makerspace. Fall pointed out how important the comment was that she received on this post, which stated:

What a great post, thank you for sharing. Your point about kids needing to feel accomplished is such an important one, and that it is by working hard and for a long time at something, like electric art, that kids can feel that they know and can teach others these skills. Your LFL project with Samuel is so inspiring to the other youth here when I shared with them what you and Stephan built. Keep up the good work! You rock!

She thought the blog comment was "a good one" because that person knew how important that "lots of books" would be.

Fall emphasized the importance of STEM knowledge in imagining the library, constructing it with an alternative energy source, and designing the paper circuit kits to be placed alongside the books. She pointed to knowledge of community as crucial, in knowing what to put in the library to help kids to "get to where I've gotten." Her actions to expand the library point to her desire to make a difference in her world. For example, she pointed to a Facebook post of a friend who delighted in learning about paper circuits. This friend had posted a video of himself completing a paper circuit with obvious delight, saying out loud as he did so, "Guys look how smart I am!" For Fall, her friend's articulation resonated with her own deeply meaningful affirmation of "feeling accomplished" when doing STEM. When Fall invited her classroom science teachers to come to the afterschool STEM club to see what she had made in this 
setting, it was a significant marker of who and how she was becoming in STEM.

\section{Local Contentious Practices}

The above-described commitment-in-practice, and how it was enacted and developed/transformed over time by Fall, also speaks to the ways in which local contentious practices implicate "broader historical forces at work, locally, in multiple ways" (Holland and Lave, 2009, p. 12). For example, as Fall argued, school science is not usually fun, accessible, or connected to action and/or consequence that brings deeper meaning and urgency to the learning process. Fall's commitment to community that she and her friends' at after-school STEM club have termed "science that matters," opened up spaces to explore, question, and critique systems of power that have zapped the life force out of science learning in formal spaces and places of education.

We also think that the specific kinds of local contentious practices which arose shaped how Fall responded in practice, giving new forms of depth and texture to her commitment-inpractice over time. How she recognized, understood, navigated, and negotiated/rejected/re-worked multiple levels of the situations that have populated her pathway over time framed and influenced how she thought about herself, her actions, and her abilities to make an impact in the world. Thus, her experiences of being and becoming in STEM have acted on her as she has acted in and with the systems of power that affect her life, her community, and others.

We note at least three forms of local contentious STEM practices. First, there is conflict over the authority to name what counts as doing STEM, for whom, where, when, and why, e.g., Whose knowledge? Whose agenda? For what reasons? ("Authority to Name").

A second local contentious practice relates to awareness around how intersectional geometries of power operate and how responses to such powered dynamics can challenge or maintain inequality. Embedded within this contentious practice are both differences in discourses/narratives that relate to people, context, science and alongside race, gender, and social class, in how science-related problems/solutions are named/framed. (“Awareness/Discourses").

A third form of local contentious practice is centered around the very distribution of access, participation and resources in science. Who has access to science knowledge and practice and how so, to the tools to learn and do science for oneself or one's community, or to the financial and social resources to do science? ("Access/Participation").

We discuss how these three local contentious practices together take shape across Fall's experiences in STEM through expanding upon a series of events related to the initial examples described above. To do so, we trace the above described events and commitment-in-practice longitudinally, as they intersect and build with each other, and in different contexts. By further narrating Fall's experiences this way, we draw attention to how Fall's enactments of her commitment-in-practice clash with history-in-institutionalized struggle, leading Fall to engage in forms of local contentious practice that become re-enactments, revisions, and refinements of her commitments over time.

\section{Local Contentious Practice: An Argument for Actuality With Engineering Design ("Authority to Name")}

\author{
"I want to help kids learn to read 'cuz lots of kids might not get it at \\ school or at home [like me]."
}

In January of 2016, Fall and Samuel wanted to enter their Little Free STEM Library project in a local entrepreneurial faire for teens. The Great Lakes Entrepreneurial Faire [the Faire] is an annual event in the state for youth to showcase their entrepreneurial projects, with monetary awards. To enter the annual Faire, youth were required to submit a two-page business plan, addressing categories such as the problem and solution, target audience, financial summary, and competition. Fall and her friend Samuel worked on their business plan over several weeks, with help from two different mentors. They found the categories (e.g., marketing, competition) difficult because they did not match their vision of their "Little Free STEM Library business." They decided to enter their project in 2016 as a notfor-profit business, with the encouragement of their mentors even though no such category existed in the submission process. As they explained in their plan:

\begin{abstract}
Our project is meant to be "non-profit." We do not want to make money from it. What we want to do is provide opportunities to the kids in our community, where there are no other opportunities. We know what it is like to not be able to get to the library and not be able to make the kind of inventions that we think up in our heads. Some of us are lucky to have (Green Club) where we can get these materials to do these things. But not everyone can get to (Green Club) either. We want to bring (Green Club) and other STEM experiences home to kids, who, like us, know that they can use STEM to make a difference in their communities.
\end{abstract}

Fall's afterschool teacher noted that "Fall was adamant that the library materials be free. While she worked on the project she told stories of how it was unfair that many kids, like herself, did not have access to books to read, and that put them in an unfair position in school." Her mentor further noted that Fall wanted others to "feel the successes"; she felt she had and "not fall victim to the challenges she experienced. Making the business for-profit actively worked against these goals."

Fall was excited for the Faire because she felt that she and her friend had developed a business model that would "actually make a real difference" in her city. Her argument for actuality was a reaction to what she perceived as business ideas that had been supported in her city traditionally, judging by what businesses she saw in town and what ideas she believed were glaringly missing. It was equally a reaction to what she and her peers perceived upon entering the building of the Faire. Walking past table after table of food and glamor-based business proposals/prototypes, Fall arrived at her designated spot in the room with a newly added layer of purpose and urgency to frame her commitmentin-practice with her Library. Standing amongst her competition, she remarked in defiance of the overwhelming tide she witnessed around her that her project would actually matter. It had a purpose she could respect, grounded in her commitment to help her community by understanding their concerns and helping 
others. She added, "no one needs another wedding planner or cupcake business." To Fall, her engineering design project had real substance, real consequences, and real impact.

Furthermore, as Fall and her peers negotiated to have their projects located side-by-side at the Faire (they were assigned spaces distributed throughout the room), she recalled that her Black peers were upset that nearly everyone in the room was White. While Fall, too, was White, she allied with her Black friends, as she then too complained that the space felt exclusive. In fieldnotes from the event, she noted everyone else "seem to know" how the judges wanted their "projects to look," pointing out how "fancy" the other project displays were, even if the substance of the display she thought might be lacking quality. She and her peers complained they were not a part of that insider knowledge. These social-spatial arrangements symbolically and physically positioned the youth as out-of-place. At the same time, she felt their projects were more substantive, and actually "made a difference" even though their presentation format were not elaborate with extra materials "none of us could afford." Further, Fall, backed up her peers when they expressed disbelief when, mid-day, judges announced that there would be prize categories for food-related and fashion-related ideas, but not for non-profit, eco-design, or high-tech ideas. As noted earlier in reference to her blog posts, she promoted and applauded her peers' projects to the world through her posts.

The atmosphere at the Faire, which she later described as standing in contrast to her commitments, did not come as a complete surprise to her, however, given that she had understood the world of business to be about profit, not helping. As observed in the quote above, a large part of the language she and her partner Samuel included in their business plan was in direct response to what they had observed was wrong with business, where the primary goal was to make profits. In the plan, Fall (and Samuel) demonstrated a commitment to expanding the library system to help others in her community, and in procuring donated and re-used materials to lessen the economic and environmental burden of producing their libraries.

On the day of the Faire, they brought their fully functioning library with them to the convention center, filled with donated science books and several mini-maker kits they assembled. Her mentor noted how hard she and Samuel worked in the days leading up to the Faire as they put finishing touches on their project, including hours fiddling with the circuitry of the lights ensuring they would all light up. They felt they had a real chance at winning an award. However, despite her high hopes, her project failed to win anything. Instead, Fall noted "cupcake" and "wedding" projects won "all the awards."

Fall was angry. During a debriefing conversation with other afterschool maker club youth after the event, she stated, "I was really mad." "They only cared about projects that made money." And, "the projects didn't really help people because they just did things that were already out there."

"(The Faire) kind of shut me down because they were giving the same groups money for doing things that are done every year anyway. Some of the projects matter but most of the projects are just about making money..."
The event was unsettling in many ways for Fall, and for her peers and mentors. She felt that the judges did not understand or care that her project addressed a "real" need in her community. They completely missed, or at least dismissed, the actuality of her work. She felt that her business plan was dismissed because her goal was not to make money but rather to help others have access to science books and mini-maker kits so that kids in her community could have opportunities to "get to where I've gotten" by having greater opportunities for reading and doing science. Her commitments came up against dominant narratives around entrepreneurship and how these narratives are embedded within institutions - the Faire which Fall and her fellow youth presenters observed and described as being structured to uphold, reproduce, and honor framings of innovation and engineering design as a purely capitalist and individualistic pursuit, a for-profit model of business as opposed to a collaborative, community effort for the collective good.

She was further upset that the detailed efforts that she and Samuel put into ensuring that the Little Free STEM Library helped others went unrecognized. They had put a handcrank powered LED light-up system around the library to get kids curious about how it worked and what was inside it. They included mini-maker kits so that kids had access to resources to make, when they likely do not have such resources at home. The books were mainly STEM books, that reflected a range of reading levels, from picture books to high school books, so that anyone could practice their reading and learn some science in the process. All these items in the Library were carefully curated by Fall and Samuel and reflected Fall's own milestones in her path to becoming somebody in STEM. These milestones were authentic to who she was, and reflected how doing "science that matters" met her needs (e.g., honing her reading skills through STEM activities) while challenging her, with support, to do things she had not done before, so she felt accomplished.

Despite her frustrations with the Faire event, Fall was still proud of her project and her efforts. As she wrote in a blog post the day of the Faire:

Today we all went to the (convention) center for the (Faire) event to show our projects! Samuel and I showed our library. We all did amazing! My group got alot of good comments about our little free library. It was the hardest I ever worked. The library will help the kids read and also make things!

Fall affirmed her commitments to helping others and to keep doing "science that mattered" in the above quote. She further enacted these commitment-in-practice by deciding to enter the even more improved Little Free STEM Library in the Faire the following year.

\section{Local Contentious Practice: New Discourses Toward Inclusivity and Criticality in Science and Engineering Participation ("Awareness/Discourses")}

"I kept working on the project for another year with Samuel and we improved it."

During the next school year, Fall and her friend wanted to improve their Library so that it had better reach and accessibility. 
At the suggestion and help of one of their mentors, they used GIS technology to determine actual locations and operational times of public libraries, bus routes/time from their homes, schools, and afterschool club, requirements for library cards (e.g., proof of residence) and fee structures associated with late books. They determined that they lived in a "library desert" and needed to create multiple Little Free STEM Libraries to serve their community well. They added wheels to the bottom of their Library so that they could change its location. They switched from handcrank to a solar power system to light up in the inside of the library as the larger concern was helping people see what was inside the library from a distance. They added more kits and refined the directions available in the kits.

Fall insisted in participation in the Faire again that next year. She worked with other peers and her mentors to organize communication to event leaders about the need for entrepreneurial categories that supported non-profit and hightech work (Calabrese Barton and Tan, 2019).

As she prepared for the event, she blogged about the changes they made to how they teach others about how and why their Little Free STEM Library matters - clear expressions to her commitment-in-practice. She noted the GIS mapping research she did (science that matters), having fun coming up with new ideas to improve it (learning more science), and how all kids deserved to read (helping others and teaching others). She also made an explicit argument for having a "social justice business" as an important descriptor for why her business is to remain not-for-profit - "it shouldn't cost them any money."

Fall also brought her school science teacher to the community center to see her library, and her presentation. She felt her teacher would have an opportunity to see a side of her that is "hidden" in school. Fall did not think that her science teacher did not care indeed, she felt her teacher was a very caring person, one who would make a visit to the community center. Rather, she thought that no one asked science teachers to care about the community and it was "just not a part of school."

Further, she noted that having had to "deal" with the Faire "made me start to think about how I can get more people to care. some people don't really care." Dealing with the Faire for Fall meant that she responded to the historical institutional narrative of profit and elitism business codes by subverting the practices of that institution (the polished business-normed 5 min speech) toward her local contentious practices for renaming what counts (caring and serving community beyond profits) and raising awareness on inequities in youth STEM engagement opportunities.

Fall was successful in enacting her contentious practices. She and Samuel were recognized by the panel of business judges. As she reflected: "I won \$125 and I think it's 'cuz I really helped people see how it was a social justice business. I also talked about how the library would help kids just like me. It was not supposed to make money. It was supposed to just help."

The ways in which Fall worked to improve the Library informed by more research were ways in which she further enacted her commitments to teach others, specifically the Faire stakeholders about the value of the Library and her commitment to help others (children with no access to reading and making materials related to STEM). Through the process, Fall had to draw from her commitments to work very hard and do science that matters to her. In this way, her commitment-inpractice functioned in effect in a positive feedback loop as they were further sharpened and deepened as she engaged in local contentious practices (see Figure 1).

\section{Local Contentious Practice: "Now I'm a Mentor and the Chief Blogger" ("Access/Participation")}

Fall blogged more than usual during the time she worked on the library. While she presented posts on projects and activities of others, she posted many blog posts about the library itself. Blogging about her work and her peer's projects was one way in which she sought to further her commitment-in-practice, to learn more about herself, more about science, practice her written communication skills and to engage in science that matters. Fall becoming Green Club's chief blogger is also a direct push back on how she had been labeled and judged wanting by teachers in reading and writing, as a $\mathrm{D}$ student.

Since she began work on the Little Free STEM Library in the 10th grade, Fall penned 42 blog posts (October 2015-May 2018). Of the 42 posts, she mentions the Little Free STEM Library in 18 posts, and in 10 posts the focus was exclusively the Little Free STEM Library.

These blog posts, kept across two and a half years, reminded the world (open readership) of: (a) how hard she has worked, (b) how important access to STEM is, (c) how important the library is, and (d) how much others appreciated her work. She points to the importance of STEM knowledge in imagining the library, constructing it with an alternative energy source, and designing the paper circuit kits. She points to knowledge of community as crucial in knowing what to put in the library to help kids to "get to where I've gotten."

She highlighted the following blogpost written by a younger maker club peer, Jasmine, who she mentored into blogging, which illustrates how, with Fall's help, she fixed the broken wheels on the Library. Fall felt it was important that the Library was something that everyone shares and owns, "Our Little Free STEM Library wheels broke...", suggesting that this is a really good example of how teaching others helps them to develop their own commitments, too.

\section{DISCUSSION}

We have shown how Fall's commitment to community and in community took shape over time and across spaces, as her person-in-history interacted with history-in-institutionalized struggle. Her resulting contentious practices reflected and challenged the intersectional geometries of power she experienced as a White girl growing up in multi-generational poverty, and shaped her engagement within a Black social network (Holland and Lave, 2009). These local contentious practices also worked to further deepen Fall's commitment-inpractice, as in concert, both her commitment-in-practice and the emergent local contentious practices authored a new chapter forward in Fall's history-in-person, in STEM. 
With Fall's story, we argue that by examining how local contentious practice takes shape over time and across spaces, we can better understand how a culture of criticality develops in the space between person and institution. This view builds on and advances how the field understands local contentious practice because it foregrounds the importance of tension in how individuals participate in cultural activity toward new social futures. Unpacking the relationality between Fall's commitmentin-practice with her local contentious practices makes visible how the space between person and institution, which we denote as person)(institution, both becomes and functions as a "space of refusal," and a "space of resistance" (Hooks, 1990). Here the backward parentheses denotes the dialogic directionality of becoming - both for Fall in authoring a new chapter in her history-as-person and for the institutions to structurally re-orient toward radical change. This person)(institution space, for Fall and for many of her peers, is one of purposeful marginality where power resides in the margins, in the forms of solidarity and collective resistance (Hooks, 1990; see also Nasir, 2011). We think of this person)(institution space as the margins from which Fall pivoted into/out of the spaces of school, afterschool STEM club, the Faire, and the blogosphere From the person)(institution margins, Fall, with her community of allies, incubated a culture of criticality, as this space became "a radical space of possibility, a space of resistance" (Hooks, 1990, p. 149).

A culture of criticality supported Fall, and those with whom she interacted in activity (e.g., mentors, peers, allies) in collectively forming and navigating new relationalities that disrupted how intersectional geometries of power manifested in her life. Her alliances with her Black peers supported her in naming and critiquing the marginality she felt at the Faire. Together, they critiqued the experience and built new local practices for disrupting the norms of the Faire the following year. As she took up the role of mentor of younger peers in the club, which often took the form of collaborating on projects rather than helper/teacher, she introduced practices which helped to further flatten hierarches of knowledge and practice in STEM. As she solicited the ideas, experiences and opinions of community members in her efforts to care for others through making, she enacted practices that allowed new discourse threads to become legitimized in both her school classroom and after school space, along with the associated hybrid forms of knowledge/expertise that aligned with these discourses. Each of these made possible new modes of access to new resources, spaces, and representatives of STEM, making STEM more accessible, visible, and doable in those around her.

Through these interactions and negotiations, Fall authored a new chapter in her STEM history-in-person, even as the structural spaces of STEM (including school, online, afterschool, and the Faire) were structurally reoriented, through such social forces in which Fall was centered, toward radical change (hence the ")(" in person)(institution) to denote such dialogic directionality).

By radical, we refer to the norms of these spaces to shift away from what is normed. These social forces result from Fall's commitment-in-practice in dialogue with her contentious local practices, affording her lenses to imagine new possibilities.
The particular institutional narratives (which are often limitations) are what shaped Fall's developing commitment-inpractice. Through that process, she developed a criticality lens that she used to inform how she enacts her commitment-inpractice. For example, with the initial foray into the Faire with her Library, the capitalistic, middle class life-style (e.g., wedding planners, cupcake bakers) institutional narrative produced tensions, and her justice-oriented entrepreneurial practices were framed as contentious. This experience informed how Fall reevaluated her commitment-in-practice and how she then layered on a critical lens to what she did next as she sought to transform what the Faire valued.

Her commitment-in-practice led to experience that brought those around her into this cultural space - seeding, sustaining, and continually shaping an I/We community STEM collective anchored in solidarity (Urrieta, 2019). This can be seen by how she co-planned, co-taught and then stepped up to take over the teaching, her classmates about energy demands in light bulbs. Fall brought along not only her peer teacher who was seized with stage-fright, but also her classmates to explore new epistemic ideas. She also embodied a new arc of participation for students labeled as struggling, such as herself as here she was the struggling reader and quiet student leading the class in science (Nasir, 2011).

Likewise, the culture of criticality impacted her mentors. They engaged in new investigations alongside her, and sought out Faire leaders to question exclusionary practices. These are actions that grew out of conversations with Fall's experience at the Faire. That translated into Fall and her community doing more research on library deserts, adding more technical features on the Library, sharing her Library in more venues, and activity seeking out prize money to expand her Library system.

Fall positioned her transformative agency as a political practice centralizing what it meant to do STEM with a commitment to community and in community. This is arguably in opposition to the ways in which powerful adults in her life have positioned "helping" as secondary to other more individualistic-framed qualities, and have positioned her as "helpful" and a "team player" as a lesser compliment to their descriptions of others as special, smart, and leaders. But, over time, Fall - with her teacher and peer allies - re-mediated these discourses, showing those around her, and the important adults close to her in her life, that her qualities as a helper also make her a transformational leader in her community - and a respected leader in STEM and literacy. Being "helpful" from a culture of criticality demanded hard work on oneself, which Fall admirably demonstrated. It was not merely an act of convenience simply because one happens to be around "to help." Equally, being helpful from a culture of criticality was highly intentional, rather than serendipitous (again, because one happened to be around). Fall's helpfulness an enactment of transformative agency - was contingent on rigorous research, learning challenging new skills that, in addition to requiring enormous effort on her part to do a range of hard work across breadth and depth, it also necessitated confronting (and re-authoring, through engagement in person)(institution margins) deficit-oriented labels attached to her person that has shadowed her identity as a STEM-doer and innovative creator. When Fall, through her commitment-in-practice and 
contentious local practices incited structural and social change across the spaces, re-orienting these spaces toward a greater possibility of supporting "science that matters." Fall's occupying of such spaces, her "appropriation and use of (such) spaces, are political acts” (Parma, as quoted in Hooks, 1990, p. 152), a reflection of a culture of criticality.

We see a culture of criticality developing when the person in this case Fall - retooled the enactment of her commitmentin-practice in savvy ways that foregrounded criticality, as a result of her shaping her commitments as a response to institutional narratives.

A shift in Fall's local contentious practices took place, reflecting her own developing criticality. She critiqued the normative view of (1) what counted as helping others; (2) what she needed to do to help others, and (3) how to communicate to others. This developing sense of criticality impacted how Fall shifted in her practices as related to discourse, access, awareness and authority. She articulated an increasingly nuanced awareness of how inequality in STEM participation operates through how non-dominant communities are mislabeled as having no value to dominant society. Through her blogging and renaming terms such as "science that matters," Fall introduced and promoted new discourses to distinguish her work and commitments, her definitions and actions that constitute helping others in her community, with social-justice oriented business models and "communicating to the world" what kids in her community who practice "science that matters" are doing. Fall also challenged authority through her practices. She questioned how school authority decided that students learn about science instead of doing science. She critiqued the Faire organizers for their profitsbiased criteria toward youth entrepreneurship. She advocated for her role as a chief blogger with the STEM club teachers and administrator as a key way for her to continue learning science and engage in "science that matters." In shifting her practices, Fall reflected on her own becoming, making a commitment to be more vocal and open with her own story and to be willing to call explicit attention to the equity issues she herself faces, alongside members of her community.

\section{CONCLUSION AND IMPLICATIONS}

Fall's story is a hopeful story of how one girl growing up in multi-generational poverty, deemed an unsuccessful student, challenged normative structures and practices in her efforts to embark on a different path toward becoming somebody in STEM. It would, however, be unethical and unjust to frame Fall's story as an exemplar of one who "pulled themselves up by their

\section{REFERENCES}

Allen, C., and Eisenhart, M. (2017). Fighting for desired versions of a future self: how young women negotiated STEM-related identities in the discursive landscape of educational opportunity. J. Learn. Sci. 26, 407-436. doi: 10.1080/ 10508406.2017.1294985

Balibar, E., Mezzadra, S., and Samaddar, R. (2012). The Borders of Justice. Philadelphia, PA: Temple University Press. bootstraps and succeeded through sheer determination." While Fall is admirably resilient, she embodied processes of becoming in relation to the other, as a humanizing, critical, and collective endeavor. As she engaged in this I/We work, she built and supported allies in her community as her core commitmentin-practice and resulting contentious local practices developed dialectically in her growing understandings of their needs and strengths. Fall's story also sheds light on spaces of refusal and resistance between person)(institution, that can nurture a culture of criticality toward radical possibilities. While Fall and her allies relished the small wins along her becoming in STEM, they nonetheless kept a firm eye toward transforming systemic inequities as an ultimate goal. Fall's story points to both the kind and degree of marginalization minoritized youth experience in their STEM engagement and raises questions for how science teachers, researchers, and educators across formal and informal spaces should consider what empowering, authentic and connected STEM experiences for all students should entail.

\section{DATA AVAILABILITY STATEMENT}

The datasets generated for this study are available on request to the corresponding author.

\section{ETHICS STATEMENT}

The studies involving human participants were reviewed and approved by Michigan State University Institutional Review Board. Written informed consent to participate in this study was provided by the participants' legal guardian/next of kin. Written and informed consent was obtained initially from Fall's parent for all data generated prior to her 18th birthday, and then from Fall, herself, as a legal adult, for all data generated thereafter. Consent includes the publication of indirectly identifiable data as well as verbatim quotes.

\section{AUTHOR CONTRIBUTIONS}

All authors listed have made a substantial, direct and intellectual contribution to the work, and approved it for publication.

\section{FUNDING}

The research in this article was funded by the National Science Foundation, HRD \#0936692.
Bang, M., Faber, L., Gurneau, J., Marin, A., and Soto, C. (2016). Community-based design research: learning across generations and strategic transformations of institutional relations toward axiological innovations. Mind Cult. Activity 23, 28-41. doi: 10.1080/10749039.2015.1087572

Calabrese Barton, A., and Tan, E. (2019). Designing for rightful presence in STEM: Community ethnography as pedagogy as an equityoriented design approach. J. Learn. Sci. doi: 10.1080/10508406.2019.15 91411 
Charmaz, K. (2017). The power of constructivist grounded theory for critical inquiry. Qualit. Inq. 23, 34-45. doi: 10.1177/1077800416657105

Hart, G. (2002). Disabling Globalization: Places of Power in Post-apartheid South Africa, Vol. 10. Berkeley,CA: University of California Press.

Holland, D., Lachicotte, J., Skinner, D., and Cain, C. (1998). Identity and Agency in Cultural Worlds. Cambridge, MA: Harvard University Press.

Holland, D., and Lave, J. (2001). History in Person: Enduring Struggles, Contentious Practice, Intimate Identities. Albuquerque, NM: School of American Research Press.

Holland, D., and Lave, J. (2009). Social practice theory and the historical production of persons. Actio: An International Journal of Human Activity Theory (2), 1-15.

Hooks, B. (1990). Yearning. Race, Gender, and Cultural Politics. Boston, MA: South End Press.

Horn, I. (2018). Accountability as a design for teacher learning: sensemaking about mathematics and equity in NCLB era. Urban Educ. 53, 382-408. doi: 10.1177/ 0042085916646625

Jurow, A. S., and Shea, M. (2015). Learning in equity-oriented scale-making projects. J. Learn. Sci. 24, 286-307. doi: 10.1080/10508406.2015.100 4677

Nasir, N. (2011). Racialized identities: Race and achievement among African American Youth. Palo Alto, CA: Stanford University Press.

National Science Board (2018). Science and Engineering Indicators 2018. NSB-20181. Alexandria, VA: National Science Foundation.
Roth, W. M. (2006). Collective responsibility and the other. Cult. Stud. Sci. Educ. 1, $607-614$.

Trueba, H. (1999). Latinos Unidos: From Cultural Diversity to the Politics of Solidarity. Lanham, MD: Rowman \& Littlefield.

Urrieta, L. (2019). Indigenous reflections on identity, trauma, and healing: Navigating belonging and power. Genealogy 3:26. doi: 10.3390/genealogy 3020026

Urrieta, L., and Noblit, G. (2018). Cultural Constructions of Identity. Oxford: Oxford University Press.

Weis, L., Eisenhart, M., Cipollone, K., Stich, A., Nikischer, A., Hanson, J., et al. (2015). In the guise of STEM education reform: opportunity structures and outcomes in inclusive STEM-focused high schools. Am. Educ. Res. J. 52, 1024-1059. doi: 10.3102/0002831215604045

Conflict of Interest: The authors declare that the research was conducted in the absence of any commercial or financial relationships that could be construed as a potential conflict of interest.

Copyright (c) 2020 Calabrese Barton, Tan and McDaniel. This is an open-access article distributed under the terms of the Creative Commons Attribution License (CC BY). The use, distribution or reproduction in other forums is permitted, provided the original author(s) and the copyright owner(s) are credited and that the original publication in this journal is cited, in accordance with accepted academic practice. No use, distribution or reproduction is permitted which does not comply with these terms. 